\section{(A) Check for updates}

Cite this: Food Funct., 2020, 11 4446

Received 11th November 2019, Accepted 14th April 2020

DOI: $10.1039 /$ c9fo02652e

rsc.li/food-function

\title{
Influences of dietary starch structure on intestinal morphology, barrier functions, and epithelium apoptosis in weaned pigs
}

\author{
Xiaoqian Gao, Bing Yu, (D) Jie Yu, Xiangbing Mao, (D) Zhiqing Huang, (D) Yuheng Luo, \\ Junqiu Luo, Ping Zheng, Jun He (D)* and Daiwen Chen*
}

\begin{abstract}
The objective of the present study was to evaluate the effects of dietary starch structure (amylose/amylopectin ratio, $\mathrm{AR}$ ) on intestinal health of weaned pigs by determining the intestinal morphology, barrier functions, epithelium apoptosis and digestive enzymes. A total of one hundred and eight pigs (initial body weight $7.51 \pm 0.05 \mathrm{~kg}$ ) were randomly allotted on the basis of their body weight $(\mathrm{BW})$ and litters to one of the six experimental diet treatments with six replicates per treatment and three pigs per replicate. The six diets included a control (corn-soybean meal basal diet, CON) diet and five experimental diets with AR being 2.90, 1.46, 0.68, 0.31 and 0.14, respectively. The diets and water were provided ad libitum for $21 \mathrm{~d}$. Results showed that pigs fed CON and AR 2.90 diets had higher $(P<0.05)$ villus height and ratio of villus height : crypt depth in the jejunum and ileum compared with the other four starch groups. Pigs of CON and AR 0.14 groups had greater $(P<0.05)$ activities of sucrase $(S A)$ and maltase $(M A)$ than the pigs of other groups. Additionally, compared with the high amylopectin (AR 0.31 and 0.14) groups, the total apoptotic percentage was significantly decreased in $(P<0.01) \mathrm{CON}$ and high amylose (AR 2.90) groups. Ingestion of $\mathrm{CON}$ and high amylose diets upregulated $(P<0.05)$ the levels of B-cell lymphoma-2 $(\mathrm{BCl}-2)$ and occludin (OCLN) gene expression in duodenum and jejunum. However, no significant differences in the level of zonula occludens 1 (ZO-1) gene expression were observed in pigs fed with different AR diets. Interestingly, CON and high amylose groups enhanced the localization of ZO-1 protein in apical intercellular region of jejunal epithelium. Together, these results suggest that diets with high amylose can influence the intestinal health of young pigs by improving their intestinal barrier functions and reducing the epithelial cell apoptosis.
\end{abstract}

\section{Introduction}

It is a well-known fact that starch is the major energy-producing component and the main digestible carbohydrate source in mixed diets for most monogastric mammals (including humans). ${ }^{1}$ For pigs, evidence indicates that when they are in an unhealthy state, such as weaning, it can contribute to intestinal dysfunction and eventually induces physiological disorders. $^{2-4}$ In this situation, diet plays an important role in the prevention and management of these disorders. As we know, starch is the major component of the diet. ${ }^{5}$ Starch is made up of two polymers: amylose which is essentially linear $\alpha$-glucan containing $\alpha$ - $(1,4)$-linkages, and amylopectin which is larger than amylose and highly branched containing $\alpha-(1,6)-$

Animal Nutrition Institute, Sichuan Agricultural University, Key Laboratory of Animal Disease-Resistance Nutrition, Ministry of Education of China, Chengdu 611130,

Sichuan, People's Republic of China. E-mail: hejun8067@163.com,

dwchen@sicau.edu.cn; Fax: +86835 2885164, +868352885106 linkages in the branching points and $\alpha$-(1,4)-linkages in the linear chains. ${ }^{6,7}$ Reports confirmed that amylopectin was more easily digested than amylose because amylose polymers had more intramolecular hydrogen bonds and less surface area. ${ }^{8,9}$ According to the nutritional features, starch can be classified into three types, such as rapidly digestible, slowly digestible and resistant starch (RS). ${ }^{4}$ Generally, RS levels are associated with the ratio of amylose to amylopectin, therefore high amylose content also has high RS content. ${ }^{10}$ Moreover, previous research has found that RS has the potential to improve intestinal health by increasing micronutrient absorption and bacterial fermentation. ${ }^{11,12}$

Our previous study, the in vivo animal trial, indicated that starch with an AR of 2.90 had a lower $\mathrm{pH}$ value and higher butyrate concentration. ${ }^{13}$ Butyrate is the fermentation product generated by bacteria, which can improve the intestinal health through facilitating a tight-junction assembly and reducing the apoptosis of intestinal cells. ${ }^{14,15}$ Moreover, Haenen et al. found that diets containing a high level of RS significantly 
increased SCFA concentrations in cecum and colon. ${ }^{16}$ Increase in SCFA, especially butyrate, promotes intestinal growth and integrity both in humans and mammals. ${ }^{17,18}$ However, a high AR diet may have adverse effects on growth performance, which can be attributed, in part, to the high amylose content decreasing the nutrient digestibility. ${ }^{19}$ Interestingly, based on the characteristics of amylose digestibility, it is very suitable to be added to animal or human diets as functional food. Thus, studying the relationship between starch and intestine in pigs may provide useful information for animal and human health. In addition, few studies have compared the effects of cornsoybean meal basal diet and semi-pure diet (maize starch) on intestinal health of weaned pigs. Because of its similar homology to human, the pigs have been increasingly used as an experimental model for humans, particularly for nutritional studies.

Therefore, the aim of the present study was to evaluate the physiological responses of weaned pigs fed with different dietary AR, and mechanisms behind these responses were investigated. Furthermore, these results may pave the way for developing amylose as a functional food additive for both animals and humans in the near future.

\section{Materials and methods}

\section{Experimental design and animal management}

A total of one hundred and eight healthy cross-bred (Duroc $\times$ Landrace $\times$ Yorkshire) pigs weaned at $21 \mathrm{~d}$ (average initial BW of 7.51 (SEM 0.05)) were blocked and assigned to one of the six treatments based on their body weight and litters. Each treatment was replicated with 6 pens of 3 pigs per replicate pen. The six treatments included a control group and five experimental groups. Pigs in CON (control, a basal diet) group were fed maize-soybean meal diet and the other five groups were fed purified maize starch diets (Table 1). High amylose maize starch with AR 3.00 and high amylopectin maize starch with AR 0.06 were purchased from Shanghai Quanwang Biotechnology Co. Ltd (Shanghai, China) and Shandong Fuyang Biological Starch Co. Ltd (Dezhou, Shangdong, China), respectively. The experimental diets were formulated to meet the National Research Council (2012) for 7-11 kg pigs. ${ }^{20}$ The amylose/amylopectin ratios in the diets of each experimental group were $2.90,1.46,0.68,0.31$ and 0.14 , respectively. All diets were free of antibiotics. The temperature was maintained at $28 \pm 1{ }^{\circ} \mathrm{C}$ and the relative humidity was controlled at $65 \%-$ $75 \%$ for the entire experiment. Pigs consumed the diets and water ad libitum for $21 \mathrm{~d}$. All pigs were checked daily for general health.

\section{Sample collection}

After $21 \mathrm{~d}$, six pigs per diet were anaesthetised by an intravenous injection of sodium pentobarbital (200 mg per kg, BW). Then, the abdomen was immediately opened to collect the intestinal sections from the gastrointestinal tract. The middle section $(2 \mathrm{~cm})$ of the duodenum, jejunum, and ileum was flushed gently with ice-cold phosphate-buffered saline (PBS), and then collected and fixed in $4 \%$ formaldehyde-phosphate buffer for intestinal histology and immunofluorescence analyses. The mucosal tissue from each segment of small intestine was gently scraped with a glass slide and then carefully washed in ice-cold PBS, followed by fixation in PBS for flow cytometry or snap-frozen in liquid nitrogen, and then stored at $-80^{\circ} \mathrm{C}$ for further analysis.

\section{Digestive enzyme activity detection}

Mucosa from the small intestine was homogenized in physiological saline according to a $1: 9$ ratio $\left(\mathrm{g} \mathrm{mL}^{-1}\right)$. The homogenate was centrifuged at $2500 \mathrm{~g}$ and $4{ }^{\circ} \mathrm{C}$ for $10 \mathrm{~min}$. The supernatant was analyzed for protein content and disaccharidase (lactase (LA), SA, and MA) activities using commercial kits (Nanjing Jiancheng Bioengineering Institute, Nanjing, China). The total protein content was measured using the Bradford Brilliant Blue method (Nanjing Jiancheng Bioengineering Institute, Nanjing, China). Enzyme activities were described as units per milligram of protein.

\section{Intestinal morphology measurement}

Intestinal morphology was measured using standard procedures. ${ }^{21}$ Briefly, fixed intestinal segments were dehydrated and embedded in paraffin, sectioned $(5 \mu \mathrm{m})$, and stained with hematoxylin and eosin (H\&E). The specimens were examined using an Olympus CK 40 microscope at $40 \times$ magnification. A minimum of 10 well-orientated villi and associated crypts from each intestinal segment were measured. The villus height and crypt depth were measured and analyzed using an Image-pro plus 6.0 (Media Cybernetics, Inc., Rockville, MD, USA).

\section{Enterocyte apoptosis detection}

The epithelial cells of duodenum, jejunum and ileum were isolated to measure the proportion of apoptotic cells by flow cytometry using the PE Annexin V apoptosis detection kit (BD Biosciences, San Diego, CA, USA) as previously described. ${ }^{22}$ Briefly, the excised fresh mucosal layer of the small intestine was immediately isolated, and then ground and filtered to form a cell suspension. The cells were carefully washed twice with ice-cold PBS and suspended in PBS at $1 \times 10^{6}$ cells per $\mathrm{mL}$, and then centrifuged at $300 \mathrm{~g}$ for 5 min discarding the supernatant. After adding $5 \mu \mathrm{L}$ of PE Annexin V and $5 \mu \mathrm{L}$ of 7-aminoactinomycin D (7-AAD) into a $100 \mu \mathrm{L}$ aliquot of the cell suspension, the mixture was incubated at room temperature for $10 \mathrm{~min}$ in a dark room. Finally, $400 \mu \mathrm{L}$ of Annexin $\mathrm{V}$ binding buffer $(1 \times)$ was added into the reaction tubes and then mixed thoroughly. The apoptotic cells were examined by CytoFLEX flow cytometry (Beckman Coulter, Inc., Brea, CA, USA) within $1 \mathrm{~h}$ and 30000 cells were used in each acquisition reading.

\section{Immunofluorescence analysis}

The localization of $Z O-1$ protein in jejunal tissues was determined by immunofluorescence as in the previous method. ${ }^{23}$ $4 \%$ formaldehyde-fixed samples were rinsed in PBS, and then 
Table 1 Ingredient and chemical composition of experimental diets (as-fed basis) ${ }^{a}$

\begin{tabular}{|c|c|c|c|c|c|c|}
\hline \multirow[b]{2}{*}{ Item } & \multirow[b]{2}{*}{$\mathrm{CON}$} & \multicolumn{5}{|l|}{ AR } \\
\hline & & 2.90 & 1.46 & 0.68 & 0.31 & 0.14 \\
\hline \multicolumn{7}{|l|}{ Ingredients (\%) } \\
\hline Corn $(7.8 \%$ crude protein) & 52.07 & - & - & - & - & - \\
\hline High amylose maize starch & - & 50.00 & 44.00 & 32.00 & 12.00 & - \\
\hline High amylopectin maize starch & - & - & 6.00 & 18.00 & 38.00 & 50.00 \\
\hline Extruded soybean & 7.00 & 6.50 & 6.50 & 6.50 & 6.50 & 6.50 \\
\hline Soybean meal & 14.00 & 14.00 & 14.00 & 14.00 & 14.00 & 14.00 \\
\hline Soybean oil & 3.00 & - & - & - & - & - \\
\hline Fish meal (62.5\%) & 4.00 & 5.00 & 5.00 & 5.00 & 5.00 & 5.00 \\
\hline Whey powder & 9.00 & 8.50 & 8.50 & 8.50 & 8.50 & 8.50 \\
\hline Blood plasma meal & 3.00 & 3.25 & 3.25 & 3.25 & 3.25 & 3.25 \\
\hline Soy protein concentrate & 3.50 & 7.50 & 7.50 & 7.50 & 7.50 & 7.50 \\
\hline Cellulose & 0.32 & 1.20 & 1.20 & 1.20 & 1.20 & 1.20 \\
\hline Limestone & 0.90 & 1.04 & 1.04 & 1.04 & 1.04 & 1.04 \\
\hline Dicalcium phosphate & 0.25 & 0.13 & 0.13 & 0.13 & 0.13 & 0.13 \\
\hline Glucose & 2.00 & 2.00 & 2.00 & 2.00 & 2.00 & 2.00 \\
\hline Salt & 0.35 & 0.35 & 0.35 & 0.35 & 0.35 & 0.35 \\
\hline L-Lys·HCl $(78 \%)$ & 0.15 & 0.04 & 0.04 & 0.04 & 0.04 & 0.04 \\
\hline DL-Met & 0.06 & 0.09 & 0.09 & 0.09 & 0.09 & 0.09 \\
\hline Choline chloride & 0.15 & 0.15 & 0.15 & 0.15 & 0.15 & 0.15 \\
\hline Vitamin and mineral premix ${ }^{b}$ & 0.25 & 0.25 & 0.25 & 0.25 & 0.25 & 0.25 \\
\hline Total & 100.00 & 100.00 & 100.00 & 100.00 & 100.00 & 100.00 \\
\hline \multicolumn{7}{|l|}{ Calculated content (as DM) ${ }^{c}$} \\
\hline $\mathrm{DE}\left(\mathrm{Mcal} \mathrm{kg}^{-1}\right)$ & 3.53 & 3.68 & 3.68 & 3.68 & 3.68 & 3.68 \\
\hline Crude protein (\%) & 20.06 & 19.37 & 19.37 & 19.37 & 19.37 & 19.37 \\
\hline $\mathrm{Ca}(\%)^{\mathrm{r}}$ & 0.75 & 0.80 & 0.80 & 0.80 & 0.80 & 0.80 \\
\hline Available P (\%) & 0.37 & 0.36 & 0.36 & 0.36 & 0.36 & 0.36 \\
\hline L-Lysine (\%) & 1.35 & 1.35 & 1.35 & 1.35 & 1.35 & 1.35 \\
\hline Methionine + cysteine (\%) & 0.75 & 0.72 & 0.72 & 0.72 & 0.72 & 0.72 \\
\hline Threonine (\%) & 0.82 & 0.82 & 0.82 & 0.82 & 0.82 & 0.82 \\
\hline Tryptophan (\%) & 0.25 & 0.25 & 0.25 & 0.25 & 0.25 & 0.25 \\
\hline Crude fiber $(\%)$ & 2.05 & 2.05 & 2.05 & 2.05 & 2.05 & 2.05 \\
\hline Total starch (\%, measured values) & 33.62 & 43.62 & 45.57 & 43.25 & 43.76 & 46.06 \\
\hline Amylose (\%, measured values) & 14.57 & 74.36 & 59.42 & 40.57 & 23.51 & 12.53 \\
\hline Amylopectin (\%, measured values) & 85.43 & 25.64 & 40.58 & 59.43 & 76.49 & 87.47 \\
\hline
\end{tabular}

${ }^{a} \mathrm{CON}$ : control group; AR: amylose/amylopectin ratio. ${ }^{b}$ Supplied (per kg diet): VA, $6000 \mathrm{IU} ; \mathrm{VD}_{3}, 400 \mathrm{IU} ; \mathrm{VE}, 10 \mathrm{IU} ; \mathrm{VK}_{3}, 2 \mathrm{mg} ; \mathrm{VB}_{1}, 0.8 \mathrm{mg} ; \mathrm{VB}_{2}$, $6.4 \mathrm{mg} ; \mathrm{VB}_{6}, 2.4 \mathrm{mg} ; \mathrm{VB}_{12}, 12 \mu \mathrm{g}$; folic acid, $0.2 \mathrm{mg}$; nicotinic acid, $14 \mathrm{mg}$; D-pantothenic acid, $10 \mathrm{mg}$. Supplied (per kg diet): $\mathrm{Fe}^{2}$ as FeSO $\mathrm{Fe}_{4} \cdot 7 \mathrm{H}_{2} \mathrm{O}$, $100 \mathrm{mg} ; \mathrm{Mn}$ as $\mathrm{MnSO}_{4} \cdot 7 \mathrm{H}_{2} \mathrm{O}, 4 \mathrm{mg} ; \mathrm{Zn}$ as $\mathrm{ZnSO}_{4}, 80 \mathrm{mg} ; \mathrm{Cu}$ as CuSO $4 \cdot 5 \mathrm{H}_{2} \mathrm{O}, 100 \mathrm{mg} ; \mathrm{Se}$ as $\mathrm{Na}_{2} \mathrm{SeO}_{3}, 0.35 \mathrm{mg}$ and I as KI, $0.3 \mathrm{mg}$. ${ }^{c}$ Values are calculated composition except total starch, amylose and amylopectin contents.

incubated with ethylenediaminetetraacetic acid (EDTA, 1 mol $\mathrm{L}^{-1}$, pH 9.0, Goodbio Technology Co., Ltd, Wuhan, China) for antigen retrieval. Tissue sections were blocked with $3 \%$ bovine serum albumin (BSA) prior to incubation with rabbit anti-ZO-1 polyclonal antibody (1:200; Abcam Plc., Cambridge, UK) overnight at $4{ }^{\circ} \mathrm{C}$. Slides were then washed three times with PBS and incubated with goat anti-rabbit IgG-FITC secondary antibody (Gooddbio Technology Co., Ltd, Wuhan, China) at room temperature for $1 \mathrm{~h}$ in the dark. After rinsing three times in PBS, the slides were stained with 4'-6-diamidino-2-phenylindole (DAPI, Gooddbio Technology Co., Ltd, Wuhan, China) at room temperature for $10 \mathrm{~min}$ in the dark, to identify nuclei. The ZO-1 immunofluorescence images were captured using the NIKON DS-U3 software laser scanning confocal microscope (NIKON ECLIPSE C1).

\section{RNA extraction}

Total RNA was isolated from duodenal, jejunal and ileal mucosa using a TRIzol reagent (Invitrogen, Carlsbad, CA,
USA). All the procedures were carried out as per the manufacturer's protocol. The concentration and purity of total RNA were determined using a spectrophotometer (Beckman Coulter DU800) based on the absorbance at $\mathrm{OD}_{260} / \mathrm{OD}_{280}$ ratio (where OD is the optical density) being within 1.8 and 2.0, and the integrity was monitored using an Agilent 2100 Bioanalyzer (Agilent Technologies, Santa Clara, CA, USA). The RNA samples were reverse transcribed into cDNA using the PrimeScript $^{\mathrm{TM}}$ RT reagent kit with gDNA Eraser (Takara Biotechnology Co., Ltd).

\section{Real-time quantitative PCR}

Real-time PCR primers were designed (Takara, Dalian, China) to assay four differentially expressed genes (Table 2). Here, $\beta$ actin was chosen as the reference gene transcript, and the relative expression ratio of the target gene in comparison with the reference gene was calculated as described previously. ${ }^{24}$ Briefly, $500 \mathrm{ng}$ RNA was reverse transcribed using a highcapacity cDNA reverse transcription kit (PN 4368814; 
Table 2 Primer sequences of genes selected for the analysis by realtime RT-PCR

\begin{tabular}{|c|c|c|c|}
\hline $\begin{array}{l}\text { Gene } \\
\text { name }\end{array}$ & Primer sequence $\left(5^{\prime}-3^{\prime}\right)$ & Accession no. & $\begin{array}{l}\text { Temp. } \\
\left({ }^{\circ} \mathrm{C}\right)\end{array}$ \\
\hline$Z O-1$ & $\begin{array}{l}\text { Forward: } \\
\text { CAGCCCCCGTACATGGAGA } \\
\text { Reverse: } \\
\text { GCGCAGACGGTGTTCATAGTT }\end{array}$ & NM_009386.2 & 59.0 \\
\hline$O C L N$ & $\begin{array}{l}\text { Forward: } \\
\text { CTACTCGTCCAACGGGAAAG } \\
\text { Reverse: } \\
\text { ACGCCTCCAAGTTACCACTG }\end{array}$ & NM-008756.2 & 59.0 \\
\hline Bax & $\begin{array}{l}\text { Forward: } \\
\text { GGTCGCGCTTTTCTACTTTG } \\
\text { Reverse: } \\
\text { CGATCTCGAAGGAAGTCCAG }\end{array}$ & NM_00146.1 & 65.0 \\
\hline$B c l-2$ & $\begin{array}{l}\text { Forward: } \\
\text { ATGTGTGTGGAGAGCGTCAA } \\
\text { Reverse: } \\
\text { GCCCATACAGCTCCACAAAG }\end{array}$ & NM_001526.1 & 55.8 \\
\hline$\beta$-Actin & $\begin{array}{l}\text { Forward: } \\
\text { TCTGGCACCACACCTTCT } \\
\text { Reverse: } \\
\text { TGATCTGGGTCATCTTCTCAC }\end{array}$ & XM_003124280.3 & 60.0 \\
\hline
\end{tabular}

${ }^{a} Z O-1$, zonula occludens 1 ; OCLN, occludin; Bax, B-cell lymphoma-2associated X protein; $B c l-2$, B-cell lymphoma-2.

Invitrogen) for each pig. Real-time RT-PCR for $Z O-1$, OCLN, $B c l$ 2 and B-cell lymphoma-2-associated X protein (Bax) as target genes and the house keeping gene were performed using an Applied Biosystems Power SYBR Green PCR Master Mix (Foster City, CA, USA) in a Bio-Rad iCycler with minor modifications (Bio-Rad, Hercules, CA, USA). Fluorescein was added at a final concentration of $10 \mathrm{nM}$ as the reference dye. Cycling conditions were as follows: $95{ }^{\circ} \mathrm{C}$ for $10 \mathrm{~s}, 40$ cycles of $95{ }^{\circ} \mathrm{C}$ for 5 $\mathrm{s}$, and then at annealing temperature (Table 2) for $10 \mathrm{~s}$, and $72{ }^{\circ} \mathrm{C}$ for $15 \mathrm{~s}$. The melting curve conditions were $95^{\circ} \mathrm{C}$ for 30 $\mathrm{s}$, at $55^{\circ} \mathrm{C}$ for $1 \mathrm{~min}$ and $95{ }^{\circ} \mathrm{C}$ for $1 \mathrm{~min}$, which were maintained to verify the purity and specificity of all the PCR products. The relative gene expressions were calculated using the $2^{-\Delta \Delta \mathrm{Ct}}$ method. $^{25}$

\section{Statistical analysis}

All data were subjected to a one-way ANOVA test for a completely randomized design using the GLM procedure of SPSS 20.0 (SPSS, Inc., Chicago, IL, USA) with each pig as the experimental unit. A difference of $P \leq 0.05$ was considered significant, whereas $P<0.10$ was considered a tendency. The results are presented as means with their pooled standard errors. Statistical differences among the treatments were distinguished by Duncan's multiple-range tests.

\section{Results}

\section{Influences of dietary $A R$ on growth performance}

Growth parameters are shown in Fig. 1. We found no differences $(P>0.05)$ in either final BW or BW gain between the

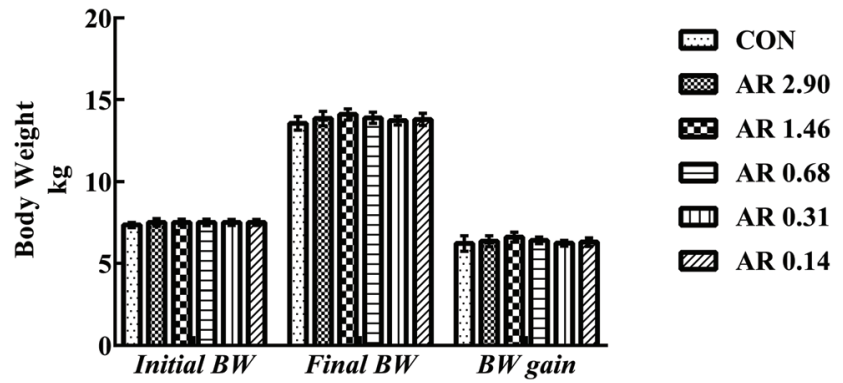

Fig. 1 Effects of dietary starch structure on the growth performance in weaned pigs throughout the entire experimental period. Values are means $(n=6)$, with standard errors represented by vertical bars. CON control group; AR amylose/amylopectin ratio; BW body weight.

CON and five experimental groups during the $21 \mathrm{~d}$ experimental period.

\section{Influences of dietary AR on intestinal morphology}

H\&E staining of the small intestine tissues after exposure to different dietary AR indicated that different dietary AR caused small architectural alterations (Fig. 2).

Next, the results of intestinal mucosal morphology analysis are provided in Table 3. In the duodenum, pigs that consumed the CON and high amylose diet (AR 2.90) had trended to increase $(P=0.067)$ villus height. However, there was no effect on the ratio of villus height to crypt depth between the CON and five starch groups in the duodenum. In the jejunum and ileum, the crypt depth of pigs in the CON and high amylose (AR 2.90 and 1.46) diets were decreased $(P=0.05$ and 0.04 , respectively), compared with pigs in the other three diets, and the ratio of villus height to crypt depth in pigs in the CON and high amylose (AR 2.90 and 1.46) diets was also greater $(P=$ 0.067 and $<0.01$, respectively) than pigs in the other three diets. However, no difference was observed between pigs in the CON and AR 2.90 groups.

Influences of dietary AR on distribution and abundance of $Z O$ 1 in the intestinal mucosa

As shown in Fig. 5, in the jejunum, an increase in the level of ZO-1 gene expression was observed in pigs fed the CON diet $(P$ $<0.05)$ compared with other experimental diets. Meanwhile, we investigated the distribution of $Z O-1$, the major tight-junction-related protein, by immunofluorescence analysis (Fig. 3) and found that in the jejunum of pigs in the high amylopectin groups, ZO-1 staining was diffused with little staining at the intercellular tight junction region, indicating disruption of the tight junction. In contrast, $Z O-1$ was highly localized to the apical intercellular region of jejunal epithelium in pigs fed the CON and high amylose diets.

\section{Influences of dietary AR on activities of digestive enzymes}

Pigs fed the high amylopectin diets (AR 0.31 and 0.14) had higher $(P<0.05)$ activities of SA and MA compared with pigs in the high $A R$ (AR 2.90) diet in the jejunum and ileum 

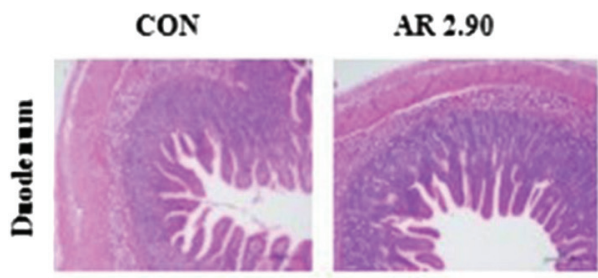
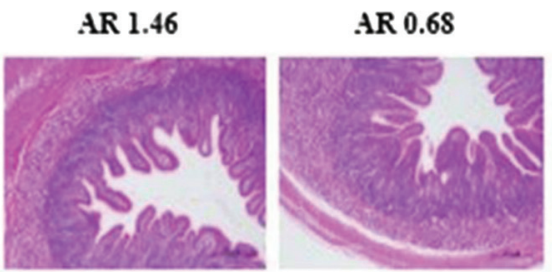

AR 031
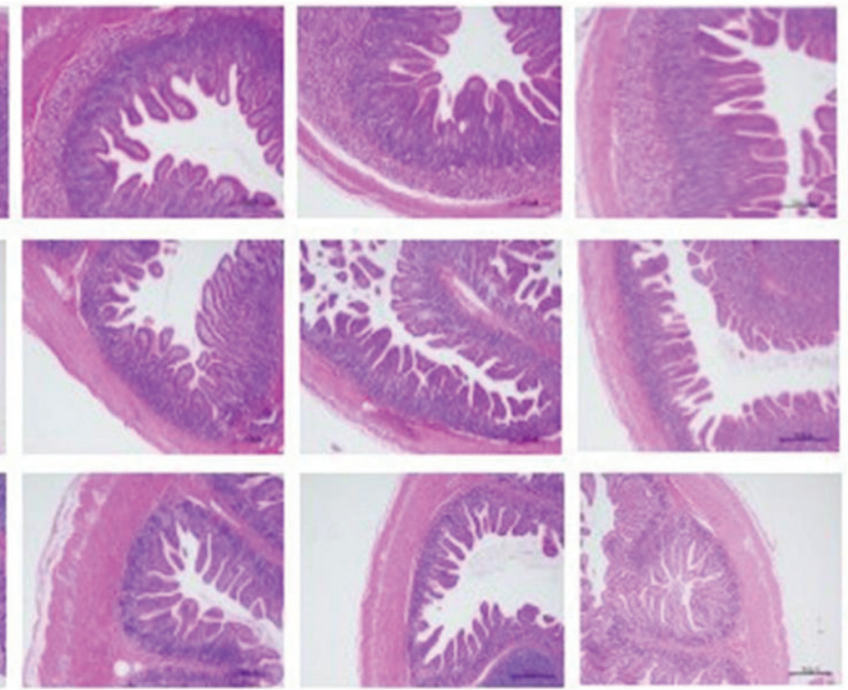

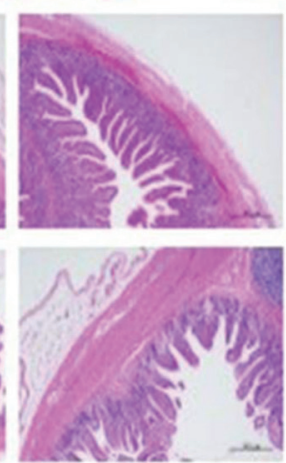

AR 0.14
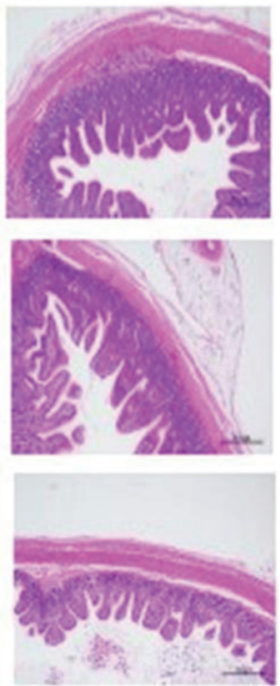

Fig. 2 Histological evaluation of small tissues $(\mathrm{HE} ; \times 40)$ in weaned pigs after exposure to dietary starch structure. CON control group; AR amylose/ amylopectin ratio. Scale bar is $500 \mu \mathrm{m}$.

Table 3 Effects of dietary starch structure on intestinal mucosal morphology in weaned pigs ${ }^{a, b}$

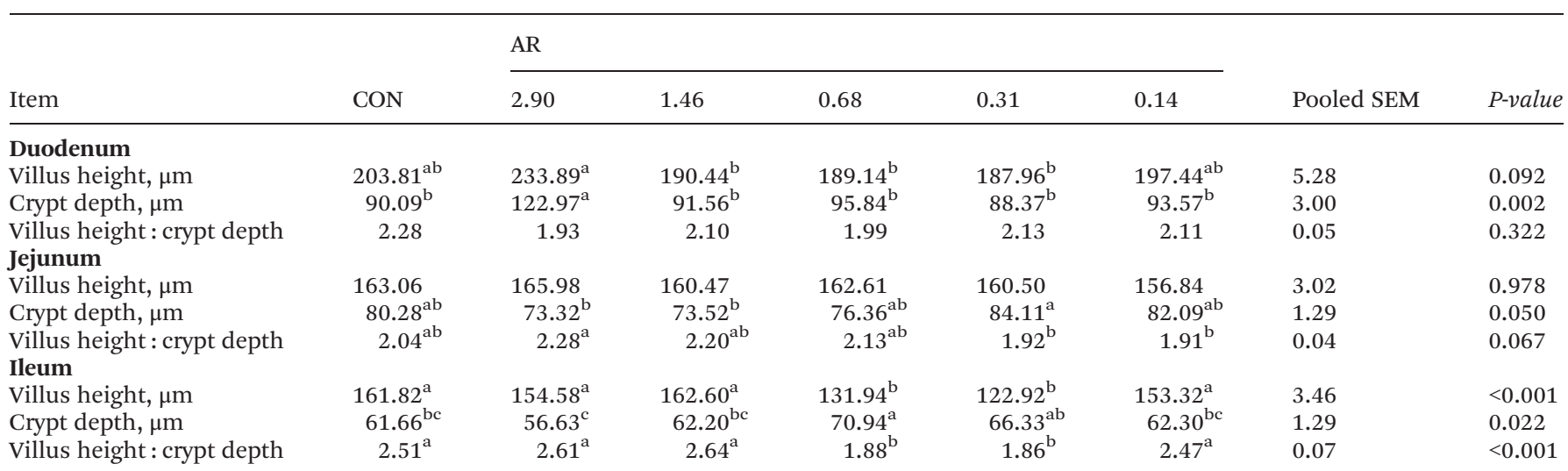

${ }^{\mathrm{a}, \mathrm{b}, \mathrm{c}}$ Mean values with unlike superscript letters were significantly different $(P<0.05) .{ }^{a} \mathrm{CON}$ control group; AR amylose/amylopectin ratio.

${ }^{b}$ Values are means of 6 replicates per treatment.

(Table 4). However, there were no differences in the activities of SA, MA and LA among the dietary treatments in the duodenum.

\section{Influences of dietary AR on intestinal epithelial cell apoptosis}

The impact of different dietary AR on the intestinal epithelial cell apoptosis are shown in Fig. 4 and Table 5. Compared to the high amylopectin groups, high amylose (AR 2.90) and CON groups decreased $(P<0.05)$ the late-stage apoptotic cell percentages, as well as the total apoptotic cell percentages in the duodenal, jejunal and ileal epithelia. Furthermore, there were no marked differences $(P>0.05)$ in the early-stage apoptotic cell percentages among the different treatments in duodenum and jejunum.
Influences of dietary AR on critical gene expression associated with intestinal barrier functions and apoptosis

The effects of different dietary AR on intestinal gene expression are shown in Fig. 5. In the jejunum, an increase in OCLN mRNA level was observed in pigs fed the CON and high amylose (AR 2.90) diets $(P<0.05)$ compared with the remaining four diets and there were no significant differences $(P>$ 0.05 ) between the CON and AR 2.90 groups. Moreover, pigs fed the CON diet showed higher $(P<0.05)$ duodenual and jejunal $B c l-2$ mRNA levels when compared with the low AR groups, and the high AR groups (AR 2.90 and 1.46) also had higher Bcl2 mRNA levels $(P<0.05)$ in the duodenum compared with the remaining three starch groups. However, no differences in Bax mRNA level was observed in pigs fed all the diets in the small intestine. 

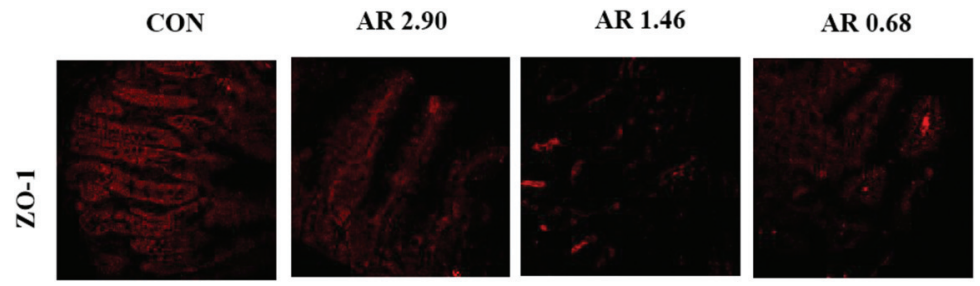

AR 031

AR 0.14
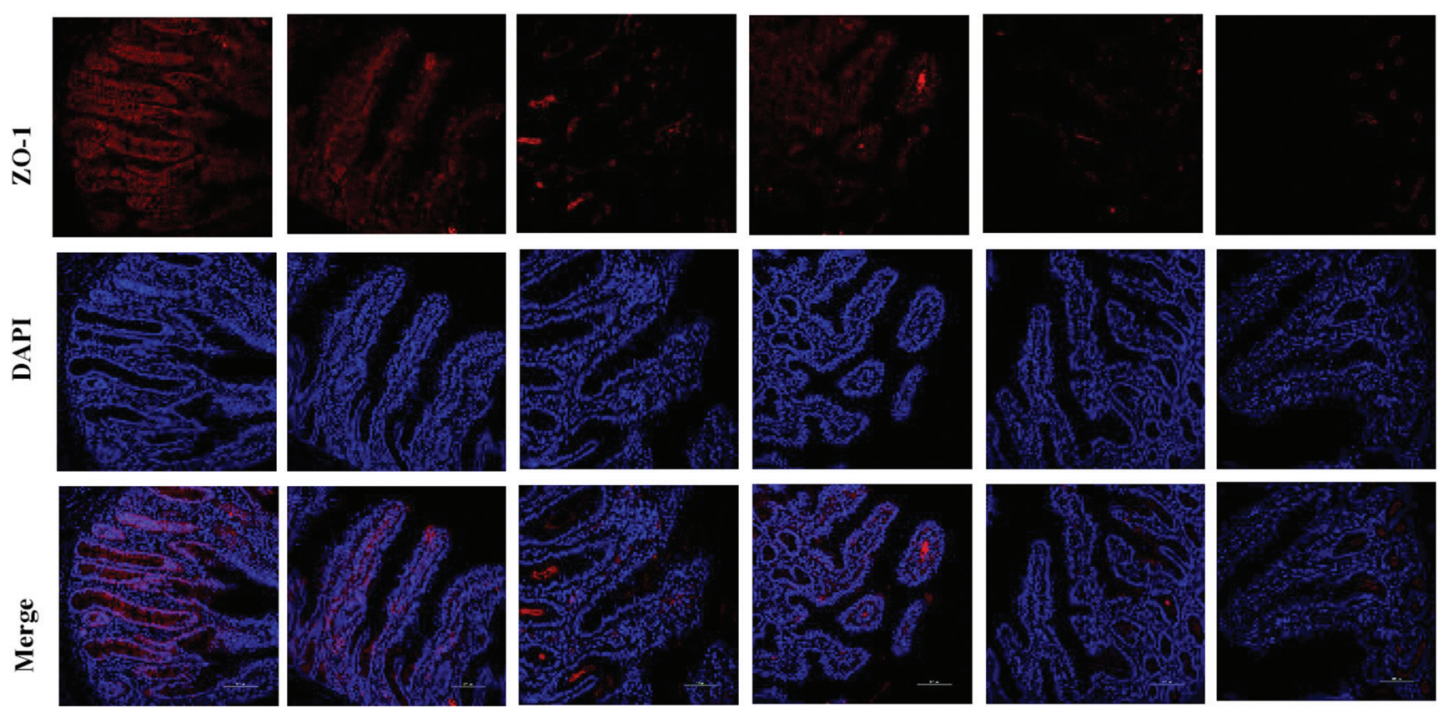

Fig. 3 Effects of dietary starch structure on tight junction distribution. Localization of ZO-1 and DAPI (DNA) within the jejunum of weaned pigs was assessed by immunofluorescence. ZO-1 protein (red), DAPI stain (blue), and merged ZO-1 protein and DAPI are shown. CON control group; AR amylose/amylopectin ratio; DAPI 4'-6-diamidino-2-phenylindole.

Table 4 Effects of dietary starch structure on the digestive enzyme activities in weaned pigs ${ }^{a, b}$

\begin{tabular}{|c|c|c|c|c|c|c|c|c|}
\hline \multirow[b]{2}{*}{ Item } & \multirow[b]{2}{*}{$\mathrm{CON}$} & \multicolumn{5}{|l|}{$\mathrm{AR}$} & \multirow[b]{2}{*}{ Pooled SEM } & \multirow[b]{2}{*}{ P-Value } \\
\hline & & 2.90 & 1.46 & 0.68 & 0.31 & 0.14 & & \\
\hline Sucrase & 16.06 & 17.05 & 20.74 & 18.88 & 17.57 & 15.93 & 1.19 & 0.881 \\
\hline Maltase & 101.36 & 79.72 & 71.12 & 97.73 & 71.71 & 99.86 & 4.91 & 0.228 \\
\hline Lactase & 15.70 & 10.28 & 8.09 & 9.50 & 9.36 & 8.98 & 1.04 & 0.614 \\
\hline \multicolumn{9}{|c|}{ Jejunum (U per mgprot) } \\
\hline Lactase & 24.48 & 27.22 & 32.28 & 34.25 & 27.70 & 31.39 & 2.15 & 0.816 \\
\hline \multicolumn{9}{|c|}{ Ileum (U per mgprot) } \\
\hline Sucrase & $35.47^{\mathrm{a}}$ & $20.68^{\mathrm{b}}$ & $36.10^{\mathrm{a}}$ & $21.90^{\mathrm{b}}$ & $43.27^{\mathrm{a}}$ & $41.59^{\mathrm{a}}$ & 2.30 & 0.007 \\
\hline Maltase & $80.20^{\mathrm{ab}}$ & $61.23^{\mathrm{bc}}$ & $70.89^{\mathrm{abc}}$ & $53.03^{c}$ & $87.53^{\mathrm{a}}$ & $79.66^{\mathrm{ab}}$ & 3.42 & 0.019 \\
\hline Lactase & $3.06^{\mathrm{b}}$ & $8.73^{\mathrm{a}}$ & $4.77^{\mathrm{b}}$ & $3.70^{\mathrm{b}}$ & $4.56^{\mathrm{b}}$ & $3.24^{\mathrm{b}}$ & 0.56 & 0.020 \\
\hline
\end{tabular}

${ }^{\mathrm{a}, \mathrm{b}, \mathrm{c}}$ Mean values with unlike superscript letters were significantly different $(P<0.05) .{ }^{a} \mathrm{CON}$ control group; AR amylose/amylopectin ratio. ${ }^{b}$ Values are means of 6 replicates per treatment.

\section{Discussion}

Although a wealth of research on starch has been investigated in both human subjects and animal model species, the relevance of pure starch with different AR on intestinal health in weaned pigs remains unclear. Much of this uncertainty can be attributed to the fact that researchers have been more focused on the function of natural food starch, but it is equally important to recognise how pure starch affects the intestinal health of humans and animals. Starch is a substantial component both in human and pig diets. It may provide pigs with more than $50 \%$ of their daily energy intake. ${ }^{26}$

However, in the present study, the growth performance of weaned pigs was not affected by different dietary AR. This should be attributed, in part, to the extremely high amylose content (over 75\%) used in this study. However, our results are in line with the previous study performed in weaned pigs. ${ }^{27}$

Intestine is not only an important organ responsible for digestion, absorption and metabolism of dietary nutrients, but also acts as a physical barrier, interacting with a complex external milieu. ${ }^{28}$ Tight junction proteins (OCLN and ZO-1) play an important role in intestinal barrier integrity, which prevents or reverses the adverse effects of pathogens. ${ }^{29}$ Thus, in the set of experiments discussed in this article, we investigated the effects of diet with different AR on intestinal health in weaned pigs. In the present study, our data on high amylose groups showed an increase ratio of villus height: crypt depth in the jejunum and ileum. Simultaneously, the level of OCLN gene 


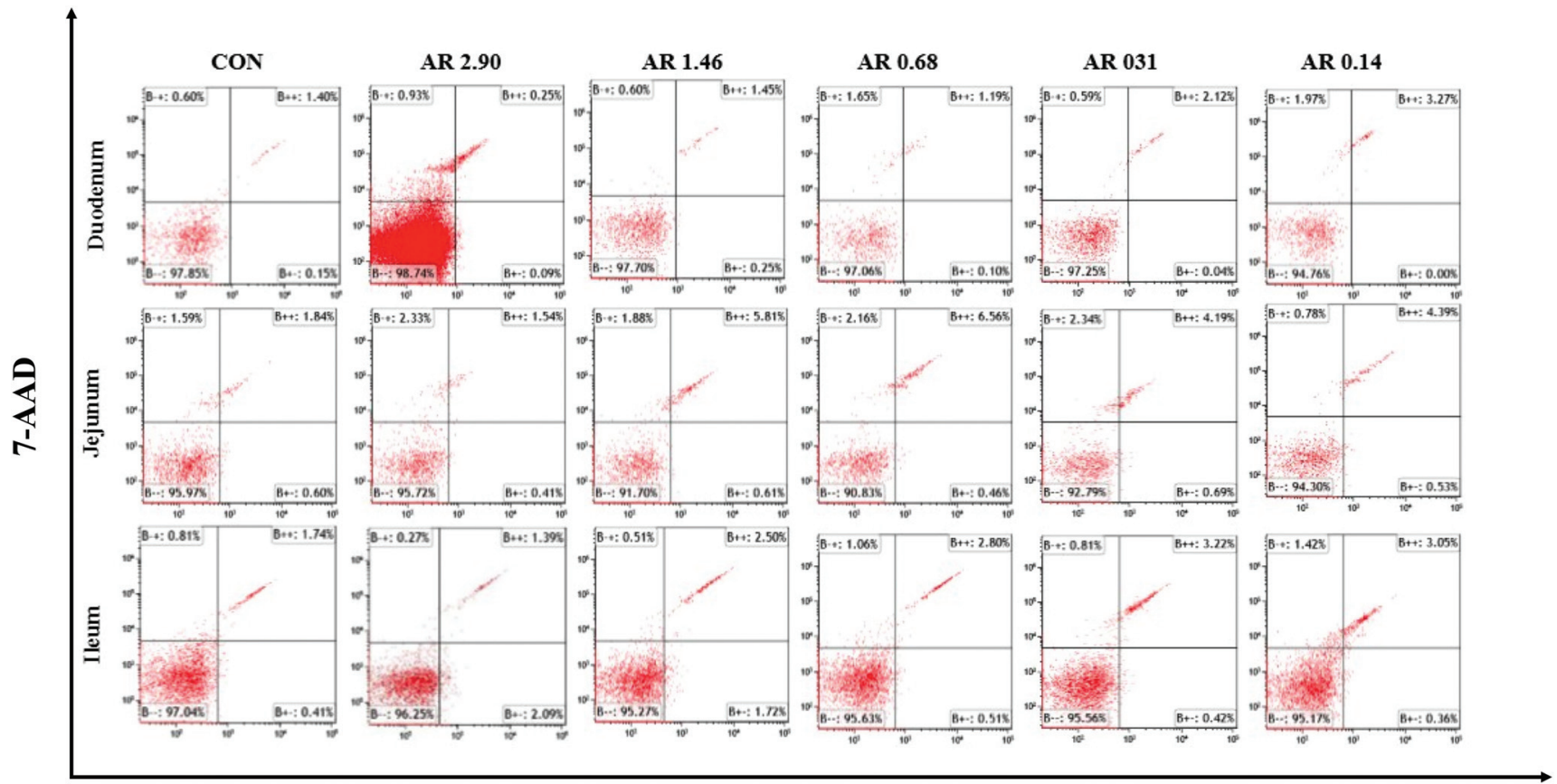

\section{PE Annexin V}

Fig. 4 Evaluation of jejunal cell apoptosis by flow cytometry in weaned pigs after exposure to dietary starch structure. Frames were divided into four quadrants: B-+ represents necrotic cells; B++ represents late-stage apoptotic cells; B-- represents normal cells; B+- represents early-stage apoptotic cells. 7-AAD 7-aminoactinomycin D; CON control group; AR amylose/amylopectin ratio.

Table 5 Effects of dietary starch structure on the enterocyte apoptosis of weaned pigs ${ }^{a, b}$

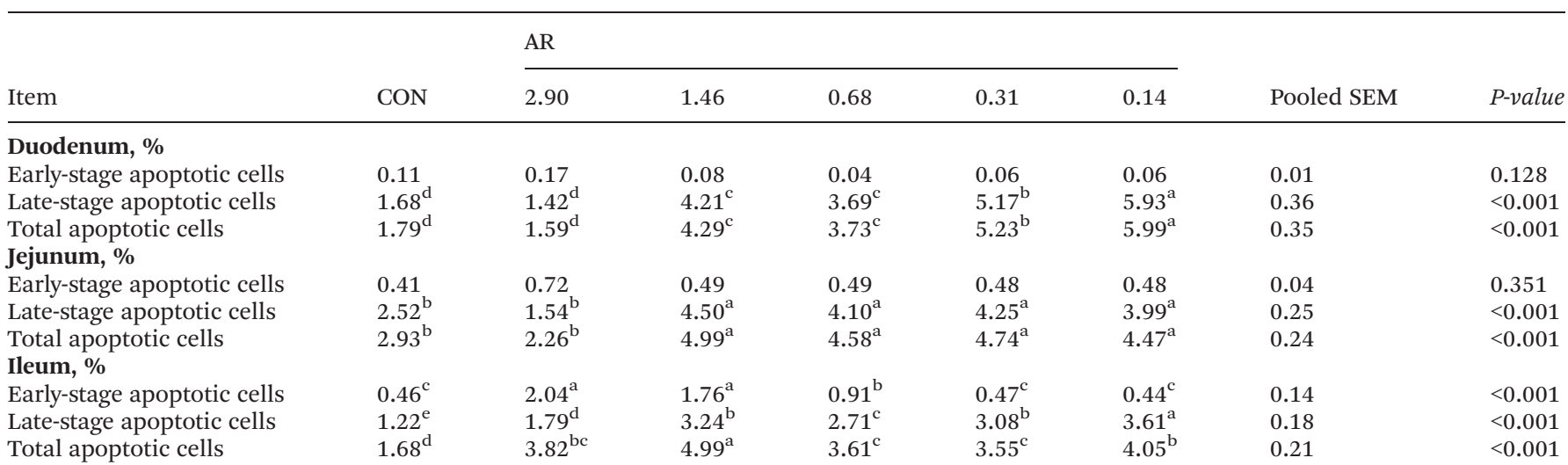

${ }^{\mathrm{a}, \mathrm{b}, \mathrm{c}, \mathrm{d}, \mathrm{e}}$ Mean values with unlike superscript letters were significantly different $(P<0.05) .{ }^{a} \mathrm{CON}$ control group; AR amylose/amylopectin ratio.

${ }^{b}$ Values are means of 6 replicates per treatment.

expression in the jejunum was higher in pigs fed the CON and high AR (AR 2.90) diets than pigs consuming low AR diets. In addition, pig fed the CON diet also had an increased level of ZO-1 gene expression in the jejunum. Immunofluorescence results were consistent with the expression of tight junction proteins. These observations support the notion that diet with high AR can improve the intestinal morphology and function. Meanwhile, previous studies have found that ingestion of a potato starch (high AR) diet may have positively affected the intestinal health in the weaned pigs. ${ }^{27}$
Apoptosis is a type of programmed cell death, which has two basic apoptotic signaling pathways: the intrinsic and the extrinsic pathways. ${ }^{30}$ The intrinsic apoptosis is activated by various intracellular stimuli, it relies on a complex composed of procaspase-9, apoptotic protease-activating factor-1 (Apaf1 ), and cytochrome c. Then, Bcl-2 family controls the release of cytochrome $\mathrm{c}$ by regulating the mitochondrial membrane permeabilization. ${ }^{31}$ Another pathway is triggered by the death receptors, especially Fas, a member of the tumour necrosis factor (TNF) receptor superfamily. ${ }^{32}$ Research certi- 


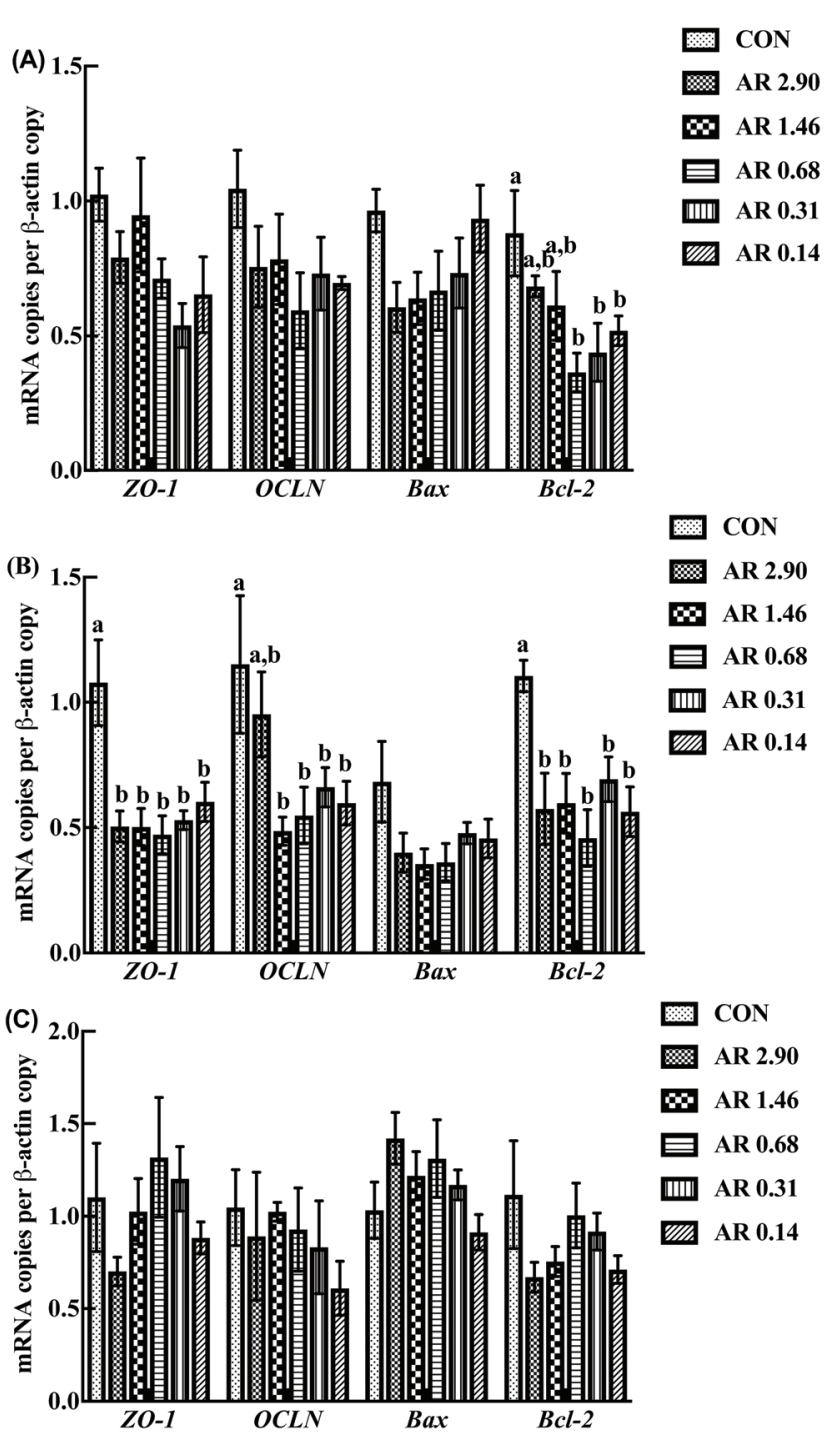

Fig. 5 Effects of dietary starch structure on intestinal gene expression in duodenum (A), jejunum (B) and ileum (C). ZO-1 zonula occludens 1; OCLN occludin; Bax B-cell lymphoma-2-associated X protein; Bcl-2 B-cell lymphoma-2. Values are means $(n=6)$, with standard errors represented by vertical bars. CON control group; AR amylose/amylopectin ratio. ${ }^{a, b}$ Mean values with unlike letters were significantly different within a cluster of bars, not across the clusters of bars $(P<0.05)$.

fied that reducing intestinal epithelial cell apoptosis may play an important role in improving bowel adaptation. ${ }^{33}$ Here, we noted that apoptosis was less prevalent in the small intestine epithelial cells in the high AR (AR 2.90) and CON diets, suggesting that high $\mathrm{AR}$ and basal diets may have a protective influence against enterocyte apoptosis. Similar results were observed in growing pigs, which showed that a diet high in amylose reduced apoptosis in colon. ${ }^{15}$ To explore the mechanisms behind these responses, we measured two critical genes involved in regulating cell apoptosis. We found that pigs fed the high AR (AR 2.90) and CON diets significantly increased the level of $\mathrm{Bcl}-2$ gene expression in the duodenum.
The enzyme activities in the digestive tract, including SA, LA and MA, were considered as important indicators of intestinal maturation and digestive function. ${ }^{34}$ Previous studies have indicated that mature enterocytes had higher brush-border enzyme activities than immature enterocytes. ${ }^{35}$ Digestive enzymes, including disaccharidases and peptidases, are secreted to the brush-border membrane to facilitate nutrient absorption. ${ }^{36}$ Previous studies have found that LA was positively correlated with villus height in weaning, whereas SA and MA were positively correlated with villus height from suckling to growing. ${ }^{36}$ In the present study, pigs fed the low AR (AR 0.14) diet had greater activities of SA and MA in jejunum and ileum in accordance with the results of villus height. The present results, however, agree with previous findings showing that ingestion of a waxy corn (low AR) had higher SA and MA activities than non-waxy corn (high AR) in weaned pigs. ${ }^{37}$

An important finding from the present study is the knowledge gained about the different effects between corn-soybean meal basal diet and semi-pure diet on intestinal health in weaned pigs. There is no doubt that basal diet is more suitable for weaned pigs as a long-term diet option. Therefore, our study once again confirms the theory that the balance of nutrient sources is more important than the balance of nutrients. Interestingly, in the present study we found that CON and high AR diets had similar effects on weaned pigs. These findings may provide an advanced insight into the health benefits of adding appropriate amount of amylose into human or animal diets.

\section{Conclusion}

Our results suggested that pigs fed high AR diet can improve weaned pig intestinal health through enhancing weaned pig intestinal morphology and barrier functions and reducing enterocyte apoptosis. Conversely, low AR may be more helpful for animal digestion. In human nutrition where health but not final BW is the main objective, high amylose is gaining popularity.

\section{Funding}

This research was supported by grants from the National Natural Science Foundation of China (Project No. 31730091).

\section{Availability of data and materials}

All data generated or analyzed during the study are included in this article.

\section{Author contributions}

JH and DWC designed the whole experiment. XQG performed the experiment, including chemical analysis, statistical ana- 
lysis and manuscript writing. BY, $\mathrm{ZQH}$ and JY verified the validity of the experiment and checked the results. PZ, JQL and YHL participated in the experimental design and provided valuable advice. All authors have read and approved the final version of the manuscript.

\section{Consent for publication}

Not applicable.

\section{Ethics approval and consent to participate}

All experimental procedures and animal care were accomplished in accordance with the Guide for the Care and Use of Laboratory Animals provided by the Institutional Animal Care Advisory Committee for Sichuan Agricultural University. The experimental protocols used in the present study were approved by the Sichuan Agricultural University Institutional Animal Care and Use Committee no. 69130079.

\section{Conflicts of interest}

The authors state that there are no conflicts of interest in this field.

\section{Acknowledgements}

We are grateful to Huailu Xin and Dan Wang for their assistance during the animal experiments. Daiwen Chen and Jun He directly supervised the project, and participated in its experimental design and data interpretation.

\section{References}

1 K. E. B. Knudsen, H. N. Lærke, S. Steenfeldt, M. S. Hedemann and H. Jørgensen, In vivo methods to study the digestion of starch in pigs and poultry, Anim. Feed Sci. Technol., 2006, 130, 114-135.

2 D. B. Anderson, V. J. Mccracken, R. I. Aminov, J. M. Simpson, R. I. Mackie, M. W. A. Verstegen and H. R. Gaskins, Gut microbiology and growth-promoting antibiotics in swine, Nutr. Abstr. Rev., 1999, 20, 101-108.

3 H. Yang, X. Xiong, X. Wang, T. Li and Y. Yin, Effects of weaning on intestinal crypt epithelial cells in piglets, Sci. Rep., 2016, 6, 36939.

4 L. B. Bindels, R. R. S. Munoz, J. C. Gomes-Neto, V. Mutemberezi, I. Martínez, N. Salazar, E. A. Cody, M. I. Quintero-Villegas, H. Kittana and C. G. de Los ReyesGavilán, Resistant starch can improve insulin sensitivity independently of the gut microbiota, Microbiome, 2017, 5, 12.
5 P. Raigond, R. Ezekiel and B. Raigond, Resistant starch in food: a review, J. Sci. Food Agric., 2015, 95, 1968-1978.

6 A. Stevnebø, S. Sahlström and B. Svihus, Starch structure and degree of starch hydrolysis of small and large starch granules from barley varieties with varying amylose content, Anim. Feed Sci. Technol., 2006, 130, 23-38.

7 R. F. Tester, J. Karkalas and X. Qi, Starch-composition, fine structure and architecture, J. Cereal Sci., 2004, 39, 151165.

8 F. Yin, Z. Zhang, J. Huang and Y. Yin, Digestion rate of dietary starch affects systemic circulation of amino acids in weaned pigs, Br. J. Nutr., 2010, 103, 1404-1412.

9 H. N. Englyst, S. M. Kingman, G. J. Hudson and J. H. Cummings, Measurement of resistant starch in vitro and in vivo, Br. J. Nutr., 1996, 75, 749-755.

10 C. Z. Yang, X. L. Shu, L. L. Zhang, X. Y. Wang, H. J. Zhao, C. X. Ma and D. X. Wu, Starch properties of mutant rice high in resistant starch, J. Agric. Food Chem., 2006, 54, 523.

11 S. Hylla, A. Gostner, G. Dusel, H. Anger, H.-P. Bartram, S. U. Christl, H. Kasper and W. Scheppach, Effects of resistant starch on the colon in healthy volunteers: possible implications for cancer prevention, Am. J. Clin. Nutr., 1998, 67, 136-142.

12 L. Yonekura and H. Suzuki, Effects of dietary zinc levels, phytic acid and resistant starch on zinc bioavailability in rats, Eur. J. Nutr., 2005, 44, 384-391.

13 X. Gao, B. Yu, J. Yu, X. Mao, Z. Huang, Y. Luo, J. Luo, P. Zheng, J. He and D. Chen, Effects of Dietary Starch Structure on Growth Performance, Serum Glucose-Insulin Response, and Intestinal Health in Weaned Piglets, Animals, 2020, 10, 543.

14 L. Peng, Z.-R. Li, R. S. Green, I. R. Holzman and J. Lin, Butyrate enhances the intestinal barrier by facilitating tight junction assembly via activation of AMP-activated protein kinase in Caco-2 cell monolayers, J. Nutr., 2009, 139, 16191625.

15 M. Nofrarías, D. Martínez-Puig, J. Pujols, N. Majó and J. F. Pérez, Long-term intake of resistant starch improves colonic mucosal integrity and reduces gut apoptosis and blood immune cells, Nutrition, 2007, 23, 861-870.

16 D. Haenen, J. Zhang, C. S. da Silva, G. Bosch, I. M. van der Meer, J. van Arkel, J. J. van den Borne, O. P. Gutiérrez, H. Smidt and B. Kemp, A diet high in resistant starch modulates microbiota composition, SCFA concentrations, and gene expression in pig intestine, J. Nutr., 2013, 143, 274-283.

17 M. Tatsuya, T. Hiroki, T. Koji and S. Kimio, Ingestion of resistant starch protects endotoxin influx from the intestinal tract and reduces D-galactosamine-induced liver injury in rats, J. Gastroenterol. Hepatol., 2010, 19, 303-313.

18 D. J. Morrison and T. Preston, Formation of short chain fatty acids by the gut microbiota and their impact on human metabolism, Gut Microbes, 2016, 7, 189-200.

19 J. M. Fouhse, M. G. Gänzle, P. R. Regmi, T. A. van Kempen and R. T. Zijlstra, High amylose starch with low in vitro digestibility stimulates hindgut fermentation and has a 
bifidogenic effect in weaned pigs, J. Nutr., 2015, 145, 24642470 .

20 National Research Council, Nutrient requirements of swine, National Academies Press, Washington, DC, 11th edn, 2012.

21 J. Pluske, I. Williams and F. Aherne, Maintenance of villous height and crypt depth in piglets by providing continuous nutrition after weaning, Anim. Sci., 1996, 62, 131-144.

22 Z. Yu, F. Wang, N. Liang, C. Wang, X. Peng, J. Fang, H. Cui, M. J. Mughal and W. Lai, Effect of selenium supplementation on apoptosis and cell cycle blockage of renal cells in broilers fed a diet containing aflatoxin B 1, Biol. Trace Elem. Res., 2015, 168, 242-251.

23 G. Wang, Y. Yu, Y. Tu, J. Tong, Y. Liu, C. Zhang, Y. Chang, S. Wang, C. Jiang and E.-M. Zhou, Highly pathogenic porcine reproductive and respiratory syndrome virus infection induced apoptosis and autophagy in thymi of infected piglets, PLoS One, 2015, 10, e0128292.

24 M. W. Pfaffl, A new mathematical model for relative quantification in real-time RT-PCR, Nucleic Acids Res., 2001, 29, e45.

25 K. J. Livak and T. D. Schmittgen, Analysis of relative gene expression data using real-time quantitative PCR and the 2 (-Delta Delta C(T)) Method, Methods, 2001, 25, 402.

26 P. A. Baghurst, K. Baghurst and S. Record, Dietary fibre, non-starch polysaccharides and resistant starch: a review, 1996.

27 J. M. Heo, A. K. Agyekum, Y. L. Yin, T. C. Rideout and C. M. Nyachoti, Feeding a diet containing resistant potato starch influences gastrointestinal tract traits and growth performance of weaned pigs, J. Anim. Sci., 2014, 92, 39063913.

28 W. Wang, S. Qiao and D. Li, Amino acids and gut function, Amino Acids, 2009, 37, 105-110.

29 D. Ulluwishewa, R. C. Anderson, W. C. McNabb, P. J. Moughan, J. M. Wells and N. C. Roy, Regulation of tight junction permeability by intestinal bacteria and dietary components, J. Nutr., 2011, 141, 769-776.

30 J. Wan, J. Zhang, D. Chen, B. Yu, X. Mao, P. Zheng, J. Yu, J. Luo and J. He, Alginate oligosaccharide-induced intestinal morphology, barrier function and epithelium apoptosis modifications have beneficial effects on the growth performance of weaned pigs, J. Anim. Sci. Biotechnol., 2018, 9, 937-948.

31 Z. Su, Z. Yang, Y. Xu, Y. Chen and Q. Yu, Apoptosis, autophagy, necroptosis, and cancer metastasis, Mol. Cancer, 2015, 14, 48.

32 J. M. Zapata, K. Pawlowski, E. Haas, C. F. Ware, A. Godzik and J. C. Reed, A diverse family of proteins containing tumor necrosis factor receptor-associated factor domains, J. Biol. Chem., 2001, 276, 24242-24252.

33 E. Q. Haxhija, H. Yang, A. U. Spencer, X. Sun and D. H. Teitelbaum, Influence of the site of small bowel resection on intestinal epithelial cell apoptosis, Pediat. Surg. Int., 2006, 22, 37-42.

34 Y. Yang, E. Kiarie, B. Slominski, A. Brûlé-Babel and C. Nyachoti, Amino acid and fiber digestibility, intestinal bacterial profile, and enzyme activity in growing pigs fed dried distillers grains with solubles-based diets, J. Anim. Sci., 2010, 88, 3304-3312.

35 M. Smith, Expression of digestive and absorptive function in differentiating enterocytes, Annu. Rev. Physiol., 1985, 47, 247-260.

36 T. Tsukahara, E. Kishino, R. Inoue, N. Nakanishi, K. Nakayama, T. Ito and K. Ushida, Correlation between villous height and the disaccharidase activity in the small intestine of piglets from nursing to growing, Anim. Sci. J., 2013, 84, 54-59.

37 C. Yang, J. He, D. Chen, B. Yu, J. Yu, X. Mao, K. Yang and Z. Yuan, Effects of corn type and fasting time before slaughter on growth and plasma index in weaning pigs, J. Anim. Sci., 2016, 94, 106-116. 